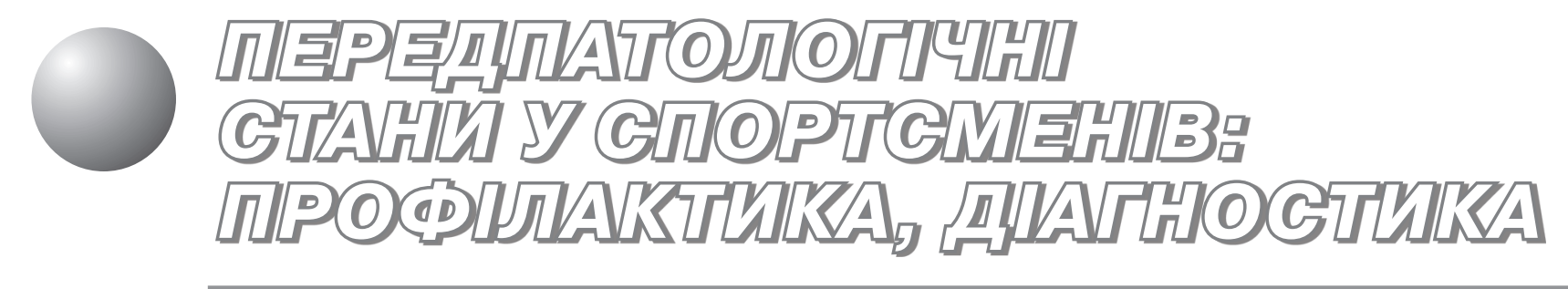

\title{
Артериальная гипертония у спортсменов: вопросы диагностики и подходы к лечению
}

\author{
А. В. Смоленский ${ }^{1}$ А. В. Михайлова ${ }^{1}$, О. И. Беличенко ${ }^{2}$, \\ А. Ю. Татаринова ${ }^{2}$ А. Б. Мирошников
}

\begin{abstract}
${ }^{1}$ ФГБОУ ВПО «Российский государственный университет физической культуры, спорта, молодежи и туризма (ГЦОЛИФК)», Москва, Россия

${ }^{2}$ НИИ спортивной медицины РГУФКСМиТ, Москва, Россия
\end{abstract}

\begin{abstract}
Резюме. Незважаючи на те що розповсюдженість артеріальної гіпертонії (АГ) у спортивній популяції значно нижче, ніж серед населення у цілому, у багатьох видах спорту, котрі характеризуються високим обсягом ізометричних навантажень (що властиве швидкісно-силовим видам спорту), поширеність підвищеного артеріального тиску (АT) і збільшення маси міокарда лівого шлуночка вище, ніж у циклічних видах спорту з переважним аеробним режимом роботи. Специфічними факторами ризику формування АГ у спортсменів $є$ значне вживання натрію, алкоголю, кофеїну і цілого ряду заборонених препаратів, включаючи еритропоетин, гормон росту та оральні контрацептиви у жінок. Закономірності формування спортивного серця, що зумовлені спрямованістю тренувальної та змагальної діяльності, у цілому не спричиняють порушення систолічної та діастолічної функції, проте підвищення АГ у спортсменів збільшує ризик розвитку гіпертрофії міокарда, що є одним із можливих протипоказань для занять видами спорту з високими статичними та динамічними навантаженнями.
\end{abstract}

Ключові слова: спорт, спортсмени, ізокінетичні та ізометричні навантаження, спортивне серце, артеріальна гіпертонія, гіпертрофія міокарда.

Summary. Despite the fact that the prevalence of hypertension in the sports population is significantly lower than in the general population, in a number of sports with high volume of isometric loads (dominant in the speed-srtrength sports events) prevalence of high blood pressure and an increase in left ventricular mass are higher than in cyclic aerobic sports events. Specific risk factors of formation of hypertension in the athletes are high intake of sodium, alcohol, caffeine, and a number of banned drugs, including erythropoietin, growth hormone, and oral contraceptives in women.

Regularities of formation of athlete's heart are caused by training and competitive activity and generally do not lead to violations of systolic and diastolic function, but the increase in blood pressure in athletes increases the risk of myocardial hypertrophy, which is one of the possible contraindications for practicing sports with high dynamic and static loads.

Key words: sport, athletes, isokinetic and isometric exercise, athletic heart, hypertension, myocardial hypertrophy.

Постановка проблемы. Лечение и профилактика артериальной гипертонии (АГ) являются одной из доминирующих задач здравоохранения в развитых странах. Увеличение распространенности АГ сопровождается пропорциональным увеличением заболеваемости и смертности от инфаркта миокарда и мозгового инсульта, которые в настоящее время рассматриваются как состояния, ассоциированные с АГ. Отчетливая связь между уровнем АД и риском смерти от сердечно-сосудистых заболеваний свидетельствует, что снижение АД является наиболее эфорективным методом профилактики сердечно-сосудистой смертности не только у лиц с повышенным АД, но также у лиц, имеющих «нормальное» АД. По данным эпидемиологических исследований, 
распространенность АГ в Российской Федерации у лиц 15 лет и старше составляет 39,5\%, что свидетельствует примерно о 40 млн больных АГ. У женщин АГ выявляется чаще, чем у мужчин (40,4 и 37,2 \% соответственно) [4].

АГ часто начинается в раннем возрасте. Настораживает значительный рост числа больных АГ среди детей и подростков. Распространенность АГ среди учащихся школ составляет 12-18 \% [1, 9]. Эпидемиологические исследования показали, что двигательная активность и кардиореспираторная тренировка находятся в обратной зависимости от уровня АД и распространенности АГ. Эти тенденции были подтверждены в рандомизированных исследованиях, показывающих, что двигательная активность может снизить АД у лиц с нормальным уровнем давления и пациентов с АГ. В целом аэробные нагрузки снижают систолическое АД (САД) примерно на 2 мм рт. ст. (до 7 мм рт. ст.) $[8,24]$. При этом наиболее значимое снижение наблюдается у больных гипертонической болезнью (ГБ). В то же время общая распространенность АГ у фризически активных лиц примерно на $50 \%$ ниже, чем в общей популяции [24]. Однако при обследовании 467 подростков, занимающихся спортом, повышение АД наблюдалось у $57(12,2 \%)$, причем у $43(79,6 \%)$ из них отмечалось стойкое повышение АД в течение года. Также было отмечено, что в группе юных спортсменов с повышенным уровнем АД преобладали скоростно-силовые нагрузки.

В отличие от изокинетических, изометрические упражнения, характерные для силовой тренировки, отличаются повышением перифрерического сосудистого сопротивления и нормальным или слегка повышенным сердечным выбросом. Это увеличение перифрерического сосудистого сопротивления вызывает переходные состояния с потенциальным риском гипертензии и увеличением постнагрузки $[6-8,11,14,15]$.

Скоростно-силовые нагрузки являются доминирующей формой деятельности в таких видах спорта, как тяжелая атлетика, спортивные единоборства, метательные дисциплины в легкой атлетике, американский фрутбол, регби. Многие виды спорта, в том числе игровые (фрутбол, лакросс, баскетбол, хоккей, хоккей на траве), включают значительные элементы как нагрузок, направленных на развитие выносливости, так и силовых упражнений.

В результате длительных интенсивных фризических нагрузок происходит фризиологическая адаптация сердца в виде его структурных и фрункциональных изменений. Формируются фризиологическая гипертрофия стенок сердца и умеренная дилатация его полостей. Эти фризиологические изменения зависят от таких фракторов, как возраст, пол, телосложение, вид спортивной дисциплины, и, в большинстве случаев, находятся в пределах референтных значений. Разные виды фризиологической адаптации сердца у атлетов формируются в зависимости от специфики спортивной деятельности.

У спортсменов, тренирующихся в циклических, преимущественно аэробных видах спорта (бег на длинные дистанции, лыжный спорт, велоспорт), в основном развивается увеличение полости левого желудочка (ЛЖ) с пропорциональным увеличением толщины его стенок. Это обусловлено повышением сердечного выброса во время упражнений, т.е. перегрузкой объемом ЛЖ, а также повышением системного АД. Развивается эксцентрическая гипертрофия ЛЖ без изменения соотношения толщины стенки ЛЖ к его диаметру.

У спортсменов, в тренировке которых преобладают статические, или изометрические, нагрузки (тяжелоатлеты, единоборцы, метатели) развивается концентрическая гипертрофрия с увеличением толщины стенки ЛЖ без изменения размера его полости, что вызвано увеличением постнагрузки на сердце за счет повышения системного АД во время фризических упражнений.

По данным эхокардиографических (ЭхоКГ) исследований, у спортсменов отмечается увеличение толщины задней стенки (ТЗС) ЛЖ и межжелудочковой перегородки (МЖП) примерно на 15-20 \% по сравнению с нетренированными людьми. Конечно-диастолический размер (КДР) ЛЖ у большинства спортсменов примерно на $10 \%$ больше, чем у нетренированных людей, но находится в пределах референтных значений.

Однако A. Pelliccia и соавт. выявили у спортсменов увеличение КДРЛЖ до 60 мм (максимально до 70 мм) без признаков дилатационной кардиомиопатии (ДКМП) и превышение толщины МЖП > 12 мм (максимально 16 мм) [20, 22]. В исследовании Basavarajaiah и соавт. из 3500 обследованных спортсменов у $1,5 \%$ отмечалось увеличение ТЗС ЛЖ до 13 мм (максимально 16 мм) [16].

Для «спортивного сердца» характерно также увеличение объема и массы правого желудочка. Систолическая и диастолическая функции обоих желудочков не нарушены ни в покое, ни при фризической нагрузке. Чаще всего при прекращении интенсивных нагрузок размеры полостей и стенок желудочков уменьшаются. Обратимость изменений считается одним из ключевых признаков «спортивного сердца». 
При этом существует небольшая группа спортсменов с выраженной гипертрофией миокарда и/или дилатацией полостей сердца, имеющих фенотипическое сходство с гипертрофической кардиомиопатией (ГКМП) и ДКМП. Между разными видами кардиомиопатий и «спортивным сердцем» есть область взаимопересечения, так называемая серая зона, которую составляют спортсмены с выраженными ЭхоКГ-признаками гипертрофии ЛЖ от 13 до 16 мм и/или дилатацией полости ЛЖ (КДРЛЖ от 55 до 60 мм) [7, $12,13,16,17,21]$.

Возможно, у спортсменов гипертросрия миокарда может быть обусловлена повышением уровня АД, что подтверждается в ряде исследований, продемонстрировавших, что у спортсменов с гипертензивной реакцией на нагрузку масса миокарда ЛЖ была достоверно выше по сравнению со спортсменами с нормотензивной реакцией.

Вероятно, повышение АД у спортсменов можно рассматривать как одну из форм перенапряжения сердечно-сосудистой системы, что может привести к ремоделированию «спортивного сердца». Одним из ключевых различий «спортивного сердца» и гипертрофии миокарда у лиц с сердечно-сосудистой патологией является отсутствие диастолической дисфункции ЛЖ у спортсменов с увеличенной массой сердца.

Материал и методы исследования. В исследование был включен 231 спортсмен восьми спортивных специализаций: бокс, борьба, тяжелая атлетика, легкая атлетика - бег на средние дистанции, велосипедный спорт, велоВМХ, парусный спорт пятиборье; возраст спортсменов от 18 до 32 лет (средний возраст 22 года), спортивная квалификация от I взрослого разряда до мастера спорта.

В основу анализа характера фризических нагрузок была положена классификация Mitchell J. H., 2005 [18], подразделяющая виды спорта в зависимости от сочетания динамических и статических нагрузок (табл.1). Классификация основана на пиковой статической и динамической нагрузке. Степень увеличения динамического компонента определяется максимальным потреблением кислорода ( $\left.\mathrm{V}_{2} \max \right)$ и степенью увеличения сердечного выброса; степень увеличения статического компонента - процентом увеличения максимального произвольного сокращения (МПС).

Всем обследованным спортсменам наряду с осмотром проводилась стандартная ЭКГ покоя, двукратное измерение АД, трансторакальная эхокардиография на аппаратах Aloka 3500 (Япония), Vivid 7 GE (США), Philips IE 33 HP (Голландия) кардиологическим секторным датчиком с частотой 3,5 МГц с использованием В- и М-режимов, импульсноволнового, цветного и тканевого допплера (ТДГ). Всем спортсменам с высоким нормальным АД (в верхней границе нормы) и повышенным уровнем АД проводилось суточное мониторирование АД (Astrocard® Holtersystem).

У спортсменов с наличием повышенного уровня АД, включая повышенное нормальное

ТАБЛИЦА 1 - Классификация видов спорта в зависимости от сочетания статических и динамических нагрузок разной интенсивности

\begin{tabular}{|c|c|c|c|}
\hline \multirow{2}{*}{$\begin{array}{l}\text { Статические } \\
\text { нагрузки }\end{array}$} & \multicolumn{3}{|c|}{ Динамические нагрузки } \\
\hline & $\begin{array}{c}\text { A. малая } \\
\left(<40 \% \text { VO}_{2} \text { max }\right)\end{array}$ & $\begin{array}{c}\text { В. умеренная } \\
\left(40-70 \% \mathrm{VO}_{2} \text { max }\right)\end{array}$ & $\begin{array}{l}\text { С. высокая } \\
\text { (> } 70 \% \text { VO }_{2} \text { max) }\end{array}$ \\
\hline $\begin{array}{l}\text { І. Малой мощности } \\
(<20 \% \text { МПС) }\end{array}$ & $\begin{array}{l}\text { Бильярд, боулинг, крикет, керлинг, } \\
\text { гольф, стрельба }\end{array}$ & $\begin{array}{l}\text { Бейсбол/софттбол", } \\
\text { настольный теннис, во- } \\
\text { лейбол }\end{array}$ & $\begin{array}{l}\text { Бадминтон, лыжные гонки (класси- } \\
\text { ческий стиль), спортивная ходьба, бег } \\
\text { (марафон), сквош, спортивное ориен- } \\
\text { тирование, теннис }\end{array}$ \\
\hline $\begin{array}{l}\text { ІІ. Средней мощности } \\
\text { (20-50\% МПС) }\end{array}$ & 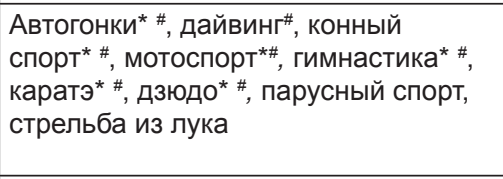 & $\begin{array}{l}\text { Американский футбол, лег- } \\
\text { кая атлетика (прыжки), фи- } \\
\text { гурное катание (парное) } \\
\text { регби\#, кросс, бег (спринт), } \\
\text { синхронное плавание\# } \\
\end{array}$ & 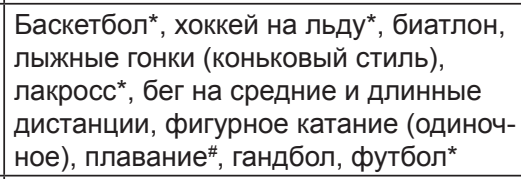 \\
\hline $\begin{array}{l}\text { III. Высокой мощности } \\
\text { (> } 50 \text { \% МПС) }\end{array}$ & $\begin{array}{l}\text { Бобслей/санный спорт* \#, боевые } \\
\text { искусства*, легкая атлетика (метание } \\
\text { ядра), гимнастика* \#, боевые искус- } \\
\text { ства*, скалолазание, водные лыжи* \#, } \\
\text { тяжелая атлетика* ", виндсерфинг* \# }\end{array}$ & $\begin{array}{l}\text { Бодибилдинг* \#, } \\
\text { горнолыжный спуск*\#, } \\
\text { скейтбординг* \#, сноубор- } \\
\text { динг \#, борьба* \# }\end{array}$ & 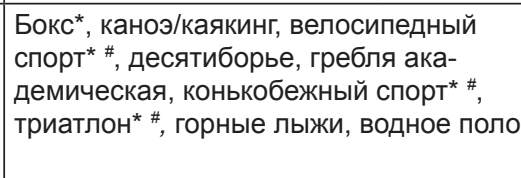 \\
\hline
\end{tabular}

* Опасность получения травмы. " Высокий риск потери сознания. 
АД, дополнительно проводился опрос с оценкой специсрических фракторов риска АГ.

Массу миокарда левого желудочка (ММЛЖ) рассчитывали по модифицированной фрормуле ASE: ММЛЖ $=0,8\{1,04$ [(КДР + ТМЖПд + + ТЗС лЖ $\left.{ }^{3}\right)^{3}-$ КДР $\left.\left.\left.^{3}\right)\right]\right\}+0,6$. Индекс массы миокарда (ИММ) левого желудочка рассчитывался к площади поверхности тела (ППТ), определяемой по фрормуле Dubois и Dubois. К гипертрофрии миокарда левого желудочка (ГЛЖ) относили мужчин с ИММ от $125\left\ulcorner\cdot \mathrm{M}^{-2}\right.$, женщин с ИММ от $110 г \cdot \mathrm{M}^{-2}$.

Диастолическая функция (ДФ) миокарда ЛЖ оценивалась по характеру трансмитрального кровотока (ТМК) в режиме импульсноволнового допплеровского сканирования (измерялись пиковая скорость раннего диастолического наполнения левого желудочка $-\mathrm{E}, \mathrm{cm} \cdot \mathrm{c}^{-1}$, пиковая скорость позднего диастолического наполнения - $\mathrm{A}, \mathrm{cm} \cdot \mathrm{c}^{-1}$; рассчитывалось их соотношение - E/A, измерялось время замедления раннего диастолического наполнения левого желудочка, $\mathrm{Dt}$, мc) и по характеру смещения митрального фиброзного кольца (в области латеральной части, межжелудочковой перегородки, передней и задней стенок левого желудочка) в режиме импульсно-волновой ТДГ. При проведении ТДГ измерялись следующие регионарные параметры систолической и диастолической фуункции ЛЖ: максимальные скорости основных «пиков» движения миокарда (систолического движения миокарда Sa и двух диастолических - е и $\mathrm{a}, \mathrm{cm} \cdot \mathrm{c}^{-1}$ ), рассчитывалось соотношение пиковых скоростей раннего ТМК и диастолического движения миокарда (E/e), соотношение диастолических «пиков» движения миокарда (е/a).

Систолический миокардиальный стресс $\left(\mathrm{MC}_{\text {сист }}\right.$, дин $\left.\cdot \mathrm{CM}^{-2}\right)$ рассчитывался по формуле:

$$
\begin{aligned}
\mathrm{MC}_{\text {сист }} & =\left(\text { САД } \cdot \text { КСРЛЖ } / 4 \cdot \text { ТЗСЛЖ }{ }_{\text {сист }}\right) \times \\
& \times\left(1+\text { ТЗСЛЖ }{ }_{\text {сист }} / \text { КСРЛЖ }\right) .
\end{aligned}
$$

Диастолический миокардиальный стресс $\left(\mathrm{MC}_{\text {диаст }}\right.$ в дин $\left.\cdot \mathrm{CM}^{-2}\right)$ рассчитывался по фрормуле:

$$
\begin{aligned}
& \mathrm{MC}_{\text {диаст }}=(\text { ДАД } \cdot \text { КДР ЛЖ } / 4 \cdot \text { ТЗС ЛЖ } \\
& \times(1+\text { ТЗС ЛЖ }
\end{aligned}
$$

Статистическую обработку полученных результатов проводили в Excel 2007 и с помощью пакета программ STATISTICA 8,0 (StatSoft Inc., USA). При выборе метода сравнения данных учитывалась нормальность распределения признака. Для проверки гипотезы о равенстве средних для двух групп использовали критерий Стьюдента (t-критерий) или непараметрический критерий Манна-Уитни; при опровержении нулевой гипотезы для анализа различий между группами использовали критерий Стьюдента. Вероятность различий подсчитывали с точностью до 0,0001. Значимыми признавались различия при $\mathrm{p}<0,05$.

Результаты исследования и их обсуждение. Среди обследованных спортсменов ( $\mathrm{n}=$ = 231) распространенность повышения АД составила 5,6 \% (13 человек). Преимущественно повышение уровня АД наблюдалось у спортсменов, в тренировке которых доминировали статические нагрузки высокой мощности в сочетании с аэробными нагрузками умеренной или высокой интенсивности.

По результатам эхокардиографического исследования спортсмены были разделены на следующие группы: женщины без ГЛЖ $(n=81)$, мужчины без ГЛЖ $(n=103)$, мужчины с пограничной ММЛЖ $(n=19)$, мужчины с ГЛЖ $(n=10)$. К пограничной ММЛЖ относили мужчин, у которых хотя бы одна стенка ЛЖ в диастолу составляла $1,2 \mathrm{~cm}$, а также мужчин с ИММ больше $120 \mathrm{r} \cdot \mathrm{M}^{-2}$. Результаты сравнительного анализа ДФ миокарда в зависимости от величины ММЛЖ представлены в таблице 2.

По показателям допплерографрии нарушений ДФ миокарда ЛЖ во всех группах спортсменов выявлено не было, что согласуется с данными большинства исследователей $[10,23]$.

ТАБЛИЦА 2 - Морфофункциональное состояние левого желудочка (по показателям тканевой допплерографии)

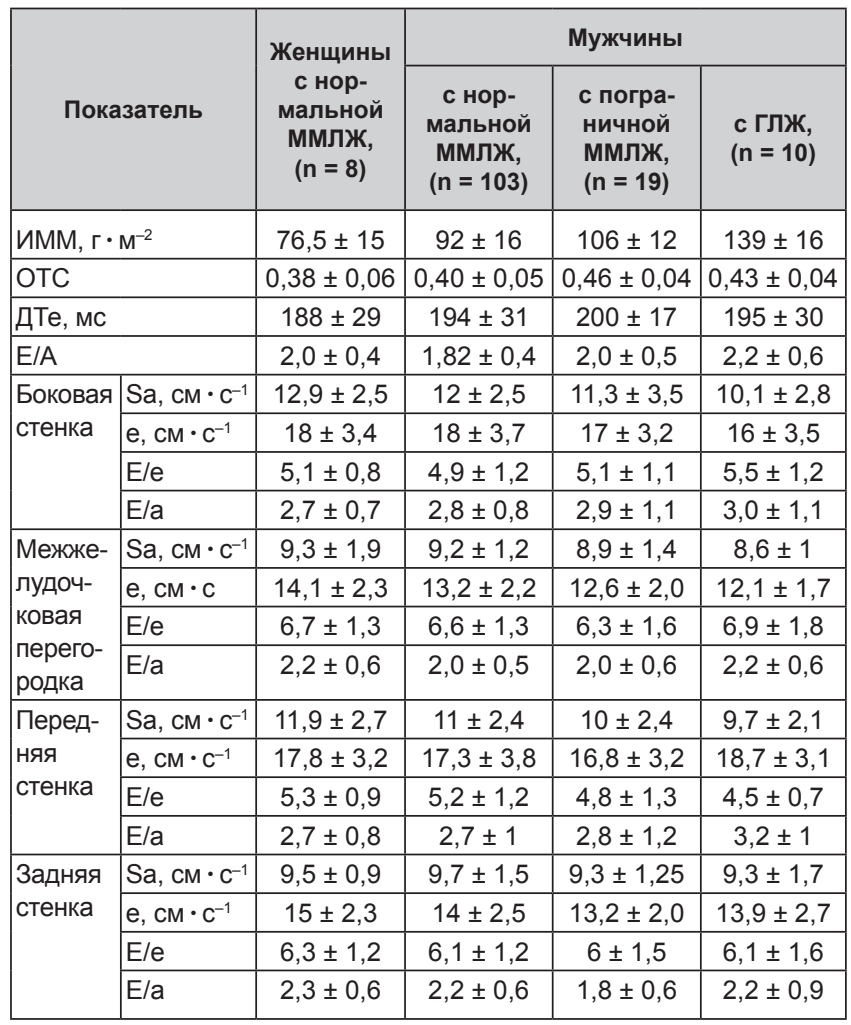


ТАБЛИЦА 3 - Морфофункциональное состояние левого желудочка (по показателям тканевой допплерографии)

\begin{tabular}{|c|c|c|c|c|}
\hline \multirow{2}{*}{\multicolumn{2}{|c|}{ Показатель }} & \multicolumn{2}{|c|}{ Мужчины } & \multirow[b]{2}{*}{$\mathbf{p}$} \\
\hline & & $\begin{array}{c}\text { с нормаль- } \\
\text { ной ММЛЖ, } \\
(n=103)\end{array}$ & $\begin{array}{l}\text { с ГЛЖ и по- } \\
\text { граничной } \\
\text { ММлЖ, } \\
\text { (n= 29) }\end{array}$ & \\
\hline \multicolumn{2}{|l|}{ ИММ, $г \cdot \mathrm{M}^{-2}$} & $92 \pm 16$ & $117 \pm 20$ & 0,0001 \\
\hline \multicolumn{2}{|l|}{$\mathrm{MCc}$} & $190 \pm 36$ & $236 \pm 32$ & 0,0001 \\
\hline \multicolumn{2}{|l|}{ МСд } & $177 \pm 31$ & $224 \pm 29$ & 0,0001 \\
\hline \multicolumn{2}{|l|}{ OTC } & $0,40 \pm 0,05$ & $0,45 \pm 0,04$ & 0,0001 \\
\hline \multicolumn{2}{|l|}{ ДТе, мс } & $194 \pm 33$ & $198 \pm 22$ & 0,607 \\
\hline \multicolumn{2}{|l|}{$\mathrm{E} / \mathrm{A}$} & $1,8 \pm 0,4$ & $2,1 \pm 0,5$ & 0,006 \\
\hline \multirow[t]{4}{*}{ Боковая стенка } & $\mathrm{S}, \mathrm{CM} \cdot \mathrm{C}^{-1}$ & $11,5 \pm 2,5$ & $10,9 \pm 3,3$ & 0,346 \\
\hline & $\mathrm{e}, \mathrm{cm} \cdot \mathrm{c}^{-1}$ & $17,7 \pm 3,7$ & $13,3 \pm 3,3$ & 0,115 \\
\hline & E/e & $4,9 \pm 1,2$ & $5,2 \pm 1,1$ & 0,387 \\
\hline & e/a & $2,7 \pm 0,8$ & $2,9 \pm 1,1$ & 0,356 \\
\hline \multirow{4}{*}{$\begin{array}{l}\text { Межжелудочковая } \\
\text { перегородка }\end{array}$} & $\mathrm{S}, \mathrm{CM} \cdot \mathrm{c}^{-1}$ & $9,2 \pm 1,2$ & $8,8 \pm 1,2$ & 0,204 \\
\hline & $\mathrm{e}, \mathrm{cm} \cdot \mathrm{c}^{-1}$ & $13,2 \pm 2,2$ & $12,4 \pm 2,1$ & 0,189 \\
\hline & E/e & $6,6 \pm 1,3$ & $6,3 \pm 2,1$ & 0,470 \\
\hline & e/a & $2,1 \pm 0,5$ & $2,2 \pm 0,9$ & 0,531 \\
\hline \multirow[t]{4}{*}{ Передняя стенка } & $\mathrm{s}, \mathrm{CM} \cdot \mathrm{c}^{-1}$ & $11,2 \pm 2,4$ & $10,0 \pm 2,3$ & 0,064 \\
\hline & $\mathrm{e}, \mathrm{cm} \cdot \mathrm{c}^{-1}$ & $17,3 \pm 3,8$ & $17,5 \pm 3,2$ & 0,804 \\
\hline & $\mathrm{E} / \mathrm{e}$ & $5,2 \pm 1,2$ & $4,8 \pm 1,6$ & 0,351 \\
\hline & e/a & $2,7 \pm 1,0$ & $3,1 \pm 1,1$ & 0,276 \\
\hline \multirow[t]{4}{*}{ Задняя стенка } & $\mathrm{s}, \mathrm{CM} \cdot \mathrm{c}^{-1}$ & $9,7 \pm 1,5$ & $9,3 \pm 1,4$ & 0,263 \\
\hline & $\mathrm{e}, \mathrm{cm} \cdot \mathrm{c}^{-1}$ & $14 \pm 2,5$ & $13,5 \pm 2,3$ & 0,154 \\
\hline & $\mathrm{E} / \mathrm{e}$ & $6,1 \pm 1,2$ & $6,0 \pm 2,0$ & 0,853 \\
\hline & e/a & $2,2 \pm 0,6$ & $2,1 \pm 0,8$ & 0,698 \\
\hline \multicolumn{2}{|c|}{$\begin{array}{l}\text { Укорочение переднезаднего } \\
\text { размера, \% }\end{array}$} & $31,2 \pm 4,1$ & $30,6 \pm 5,4$ & 0,543 \\
\hline \multicolumn{2}{|c|}{$\begin{array}{l}\text { Фракция выброса (Симпсон), } \\
\%\end{array}$} & $60,9 \pm 4,7$ & $58,3 \pm 5,1$ & 0,013 \\
\hline \multicolumn{2}{|c|}{ Минутный объем крови, л } & $4,6 \pm 1,2$ & $4,8 \pm 1,3$ & 0,288 \\
\hline
\end{tabular}

Статистически значимых различий между группами по показателям диастолической фрункции обнаружить не удалось. Однако с нарастанием массы миокарда прослеживается тенденция к снижению скорости систолического движения миокарда Sa и диастолического пика е в области боковой стенки МФК межжелудочковой перегородки и в меньшей степени - в области задней стенки.

В последующем для более наглядного сравнительного анализа спортсмены были разделены на две группы: мужчины без ГЛЖ $(n=103)$, мужчины с пограничной ММЛЖ и с ГЛЖ $(\mathrm{n}=29)$. Результаты сравнительного анализа ДФ миокарда ЛЖ представлены в таблице 3.

При проведении корреляционного анализа между показателями ММЛЖ и соотношения пиков $\mathrm{E} / \mathrm{A}$ корреляции выявлено не было ( $r=$ $=0,022, p=0,741)$. Статистически значимых отличий по другим параметрам, характеризующим ДФЛЖ, также обнаружить не удалось. Была выявлена слабая, но статистически значимая корреляция показателей ММЛЖ и значения скорости Sa латеральной части МФК ( $r=-0,174$, $\mathrm{p}=0,013)$. Также при сравнительном анализе фрракции выброса ЛЖ (по Симпсону) оказалось, что она статистически значимо ниже в группе спортсменов повышенной ММЛЖ. Скорость Sa у спортсменов с пограничной ГЛЖ статистически значимо не отличается от скорости в группе с нормальной массой миокарда ЛЖ.

Наиболее достоверным дифрференциальным критерием патологической ГЛЖ от физиологической следует считать снижение средней систолической скорости движения ФК менее $9 \mathrm{~cm} /$ с (чувствительность $87 \%$ и специфичность $97 \%$ [23]. В нашем исследовании средняя систолическая скорость движения МФК (латеральной части) у спортсменов с ГЛЖ составила $10,1 \pm 2,8 \mathrm{~cm} \cdot \mathrm{c}^{-1}$, что, возможно, обусловлено начальными признаками гипертонического ремоделирования левого желудочка. По всем остальным параметрам ДФ миокарда ЛЖ в группе спортсменов с ГЛЖ не нарушена.

Из 13 спортсменов с повышенным уровнем АД, верифицированным по данным суточного мониторирования АД, у семи спортсменов была выявлена как пограничная ГЛЖ, так и ГЛЖ, что и послужило основанием для назначения гипотензивной терапии ингибитором ангиотензин превращающего фермента (АПФ) - эналаприлом в дозе 5 мг $\cdot$ сут $^{-1}$. Оценка эфффективности трехмесячной терапии представлена на рисунке 1.

По результатам наших предыдущих исследований, полученных при обследовании 47 спортсменов, занимающихся греблей академической (в возрасте 17-19), высокое нормальное АД выявлялось в $8,5 \%$, а АГ І степени - в $25,6 \%$ случаев. Наряду с этим у спортсменов-гребцов с повышенным уровнем АД индекс ММЛЖ составил 89,07 против $74,60 \Gamma \cdot \mathrm{M}^{-2}$ у спортсменов с нормальным уровнем АД [3]. При этом корреляционной зависимости между показателями ММЛЖ и уровнем физической работоспособности у спортсменов с повышенным АД выявлено не было $(r=0,17)$.

По результатам нашего исследования следует предположить, что у спортсменов с АГ наряду с особенностями тренировочных нагрузок имело место преобладание изометрических и скоростно-силовых нагрузок, которые, возможно, способствовали развитию АГ, а гипертрофия миокарда с АГ обусловлена увеличением постнагрузки. Наличие повышенного уровня АД и увеличение ММЛЖ, расцененное нами как поражение «органов мишеней», позволило использовать ингибитор АПФ - эналаприл в качестве 
САД, мм рт. СТ.

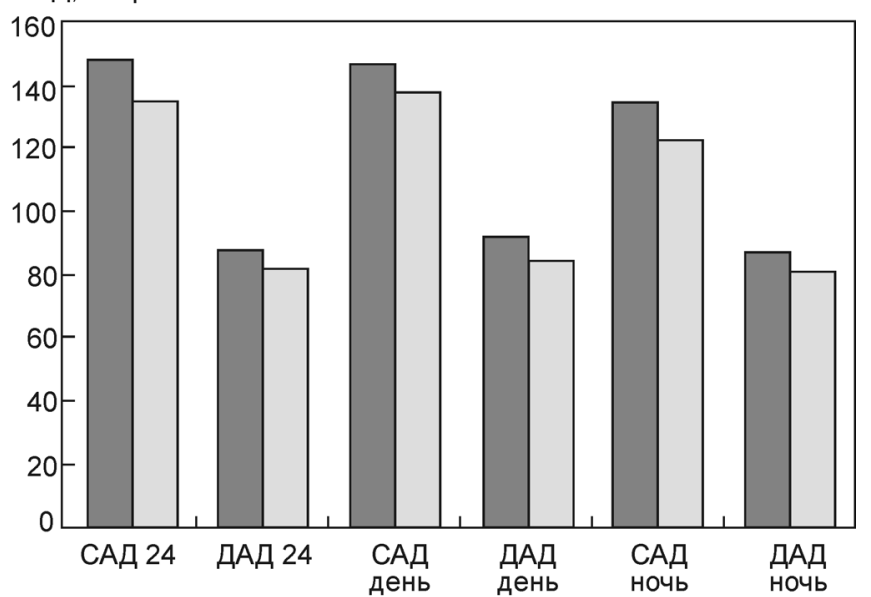

До лечения

После лечения

Рисунок 1 - Динамика показателей АД спортсменов до и после лечения:

САД - систолическое давление, ДАД - диастолическое давление

препарата выбора. Результаты трехмесячного лечения привели к достоверному снижению суточных показателей АД, однако мы не наблюдали регресса гипертрофии миокарда. При оценке уровней АД и степени АГ у спортсменов должны быть использованы стандартные критерии, изложенные в рекомендациях Всероссийского научного общества кардиологов [2], где также описывается тактика наблюдения за спортсменами с повышенным уровнем АД.

Прежде чем приступить к тренировкам и соревновательной деятельности, спортсменам рекомендуется стандартное измерение АД и, в случае его повышения (> 140/90 мм рт. ст.), целесообразно провести «внеофисные» измерения АД, чтобы исключить гипертонию «белого халата». Спортсменам с уровнем АД в пределах 120-139/80-89 мм рт. ст. следует рекомендовать изменить образ жизни и минимизировать возможные фракторы риска АГ, без изменения двигательной активности. В случае устойчивого повышения АД рекомендуется проведение ЭхоКГ для дифференциальной диагностики «спортивного сердца» от гипертрофии миокарда (ГМЛЖ). Наличие ГМЛЖ является показанием к ограничению фризических нагрузок и, возможно, к фрармакотерапии.

Наличие АГ І степени при отсутствии поражения «органов-мишеней», включая ГМЛЖ, или сопутствующих заболеваний сердца, не ограничивает спортсменов от тренировочной и соревновательной деятельности, однако рекомендуется измерение АД каждые 2-4 мес. для контроля воздействия фризических нагрузок на АД.
Спортсмены с более тяжелой АГ (II-III степени), даже без доказательств поражения «органов-мишеней», таких, как ГМЛЖ, должны быть отстранены от статических нагрузок высокой интенсивности (виды спорта классов IIIA, IIIB, IIIC) пока не нормализуется уровень АД как за счет изменения образа жизни, так и лекарственной терапии.

При назначении гипотензивных препаратов необходимо учитывать, что спортсмены, входящие в регистрируемый пул тестирования международной фредерации или выступающие на международном уровне, могут получить разрешение на терапевтическое использование только в соответствии с правилами своей международной федерации. Что касается молодых спортсменов, то Американская академия педиатрии рекомендует допускать детей и подростков, имеющих АГ, к тренировкам и соревнованиям при наличии доказательств отсутствия поражения «органов-мешеней» или сопутствующих заболеваний сердца. Контроль ЭКГ рекомендовано проводить каждые 2 мес. Молодым людям с тяжелой АГ не рекомендуются виды спорта с высокими статическими (изометрическими) нагрузками, даже если нет никаких доказательств поражения «органовмишеней»[5].

Выводы. Распространенность АГ у спортсменов достаточно низкая и составляет на $50 \%$ меньше, чем среди населения в целом, но значительно увеличивается с возрастом. Однако это вовсе не означает, что проблема АГ не актуальна в спортивной популяции, поскольку в структуре внезапной кардиальной смерти спортсменов в возрасте до 35 лет недифрференцированная гипертрофия миокарда составляет $8 \%$ (по данным аутопсии) и является, по сути, единственной доказанной причиной внезапной смерти. Крупные эпидемиологические исследования убедительно продемонстрировали, что ГМЛЖ является независимым фактором риска развития сердечно-сосудистых заболеваний. По данным Фремингемского исследования, увеличение ММЛЖ на $50\left\ulcorner\cdot \mathrm{M}^{-2}\right.$ сопровождается увеличением относительного четырехлетнего риска сердечно-сосудистых заболеваний в 2,21 раза для женщин и 1,73 раза для мужчин. ГМЛЖ является независимым фрактором риска сердечной недостаточности, ишемической болезни сердца (ИБС), желудочковых аритмий и внезапной смерти. При наличии ГМЛЖ риск застойной сердечной недостаточности повышается в пять раз. При наличии сопутствующей стенокардии летальность выше в три раза, при наличии инфаркта миокарда в анамнезе - в четыре раза. Основной 
причиной внезапной смерти спортсменов старше 35 лет является ИБС, и не исключено, что развитие коронарного атеросклероза у спортсменов обусловлено вовремя не диагностированной АГ и наличием ГМЛЖ.

Следовательно, необходимо тщательно контролировать АД у спортсменов, включая детей и подростков, особенно в тех видах спорта, где в системе подготовки превалируют скоростно-силовые и изометрические нагрузки. Диагностические процедуры должны включать ЭхоКГ и нагрузочное тестирование. Спортивная деятельность может быть разрешена только В случае хорошо контролируемого АД и низкого риска сердечно-сосудистых осложнений. Сегодня высказывается предположение, что

\section{Литература}

1. Александров А. А. Эпидемиология и профилактика повышенного артериального давления у детей и подростков / А. А. Александров, В. Б. Розанов // Рос. педиатр. журн. - 1998. - № 2. - С. 16-20.

2. Национальные рекомендации по допуску спортсменов с отклонениями со стороны сердечно-сосудистой системы к тренировочно-соревновательному процессу // Рацион. фрармакотерапия в кардиологии. - 2011. - Т. 7, № 6: прилож. - С. 4-56

3. Смоленский А. В. Морфоофункциональные отличия юных гребцов с повышенным уровнем артериального давления / А. В. Смоленский, С. Ю. Золичева, А. В. Михайлова [и др. ] // Физиология человека. - 2010. - Т. 36, № 4. - С. 107-110.

4. ШальноВа С. А. Артериальная гипертония: распространенность, осведомленность, прием антигипертензивных препаратов и эффрективность лечения среди населения Российской Федерации / С. А. Шальнова, Ю. А. Баланова, В. В. Константинов [и др.] // Рос. кардиол. журн. 2006. - № 4. - C. 45-50.

5. American Academy of Pediatrics Committee on Sports Medicine and Fitness. Athletic participation by children and adolescents who have systemic hypertension // Pediatrics. 1997. - Vol. 99. - P. 637-638.

6. Basavarajaiah S. Prevalence of hypertrophic cardiomyopathy in highly trained athletes: relevance to pre-participation screening / S. Basavarajaiah, M. Wilson, G. Whyte [et al.] // J. Amer. Coll. Cardiol. - 2008. - Vol. 5. - P. 1033-1039.

7. Baggish A. L. Training-specific changes in cardiac structure and function: a prospective and longitudinal assessment of competitive athletes / A. L. Baggish, F. Wang, R. B. Weiner [et al. ] / J. Appl. Physiol. - 2008. - Vol. 104. P. 1121-1128.

8. Cornelissen V. A. Effects of endurance training on blood pressure, blood pressure-regulating mechanisms, and cardiovascular risk factors / V. F. Cornelissen, R. H. Fagard // Hypertension. - 2005. - Vol. 46. - P. 667-675.

9. Falkner B. Hypertension in children and adolescents: epidemiology and natural history // Pediatr Nephrol. 2010. - Vol. 25(7). - P. 1219-1224.

10. Indermühle $A$. The relative myocardial blood volume differentiates between hypertensive heart disease and athlete's включение умеренных аэробных нагрузок после интенсивной скоростно-силовой тренировки может быть одним из подходов к профилактике АГ у спортсменов.

Вопросы, связанные с фрармакотерапией АГ у спортсменов, являются предметом для дальнейшего изучения, поскольку доказательная база явно недостаточна. По мнению ряда исследователей [19], приоритетным является назначение ингибиторов ангиотензин-превращающего фермента, блокаторов АТ1-ангиотензиновых рецепторов и дигидропиридиновых блокаторов кальциевых каналов, поскольку использование других препаратов в частности диуретических средств и бета-адреноблокаторов ограничено правилами ВАДА.

\section{References}

1. Aleksandrov A. A. Epidemiology and prevention of elevated blood pressure in children and teenagers / A. A. Aleksandrov, V. B. Rozanov // Ros. pediatr. zhurn. 1998. - N 2. - P. 16-20.

2. National recommendations for admission of athletes with cardiovascular system deviations to training and competitive activity // Ratsionalnaya farmakoterapiya $\vee$ kardiologii. - 2011. - Vol. 7, N 6: supplement. - P. 4-56

3. Smolensky A. V. Morphofunctional difference of young rowers with elevated blood pressure / A. V. Smolensky, S. Y.Zolicheva, A. V. Mikhailova [et al. ] // Fiziologiya cheloveka. 2010. - Vol. 36, N 4. - P. 107-110.

4. Shalnova S. A. Arterial hypertension: prevalence, intake of respective preparations and treatnment efficiency in Russian Federation / S. A. Shalnova, Y. A. Balanova, V. V. Konstantinov [ et al. ] / / Ros. kardiol. zhurn. - 2006. N 4. - P. 45-50.

5. American Academy of Pediatrics Committee on Sports Medicine and Fitness. Athletic participation by children and adolescents who have systemic hypertension // Pediatrics. 1997. - Vol. 99. - P. 637-638.

6. Basavarajaiah S. Prevalence of hypertrophic cardiomyopathy in highly trained athletes: relevance to pre-participation screening / S. Basavarajaiah, M. Wilson, G. Whyte [et al.] // J. Amer. Coll. Cardiol. - 2008. - Vol. 5. - P. 1033-1039.

7. Baggish A. L. Training-specific changes in cardiac structure and function: a prospective and longitudinal assessment of competitive athletes / A. L. Baggish, F. Wang, R. B. Weiner [et al.] / J. Appl. Physiol. - 2008. - Vol. 104. P. 1121-1128.

8. Cornelissen V. A. Effects of endurance training on blood pressure, blood pressure-regulating mechanisms, and cardiovascular risk factors / V. F. Cornelissen, R. H. Fagard // Hypertension. - 2005. - Vol. 46. - P. 667-675.

9. Falkner B. Hypertension in children and adolescents: epidemiology and natural history // Pediatr Nephrol. 2010. - Vol. 25(7). - P. 1219-1224.

10. Indermühle $A$. The relative myocardial blood volume differentiates between hypertensive heart disease and athlete's heart in humans / A. Indermühle, R. Vogel, P. Meier [et al.] // Eur. Heart J. - 2006. - Vol. 27(13). - P. 15711578. 
heart in humans / A. Indermühle, R. Vogel, P. Meier [et al.] // Eur. Heart J. - 2006. 0150 Vol. 27(13). - P. 1571-1578.

11. Izzo J. Hypertension in athletes /J. Izzo // J. Clin. Hypertens. - 2009. - Vol. 11. - P. 226-233.

12. Kervancioglu P. Echocardiographic evaluation of left ventricular morphology and function in young male footbal players and runners / P. Kervancioglu, E. S. Hatipoglu // Cardiol. J. - 2007. - Vol. 14. - P. 37-43.

13. Lauschke J. Athlete's heart or hypertrophic cardiomyopathy? / J. Lauschke, B. Maisch / / Clin. Res. Cardiol. 2009. - Vol. 98. - P. 80-88.

14. Lehmann M. Incidence of hypertension in 810 male sportsmen. / M. Lehmann, J. Keul // Z. Kardiol. - 1984. Vol. 73. - P. 137-141.

15. Longás Tejero M. A. Prevalence of hypertensive response to exercise in a group of healthy young male athletes. Relationship with left ventricular mass and prospective clinical implications // M. A. Longás Tejero, J. A. Casanovas Lenguas // Rev. Esp. Cardiol. - 1996. - Vol. 49(2). - P. 104-10.

16. Maron B. J. The heart of trained athletes: cardiac remodeling and the risks of sports, including sudden death / B. J. Maron, A. Pelliccia / / Circulation. - 2006. - Vol. 114. P. $1633-1644$.

17. Maron B. J. Sudden death in young athletes / B. J. Maron / / N. Engl. J. Med. - 2003. - Vol. 349. - P. 1064-1075.

18. Mitchell J. H. Task Force 8: classification of sports / J. H. Mitchell, W. Haskell, P. Snell, S. P. Van Camp // J. Amer. Coll. Cardiol. - 2005. - Vol. 45(8). - P. 1364-1367.

19. Niedfeldt M. W. Managing hypertension in athletes and physically active patients / M. W. Niedfeldt // Amer. Fam. Physician. - 2002. - Vol. 66. - P. 445-452.

20. Pelliccia $A$. The upper limit of physiologic cardiac hypertrophy in highly trained elite athletes / A. Pelliccia, B. J. Maron, A. Spataro [et al.] / / N. Engl. J. Med. - 1991. Vol. 324. - P. 295-301.

21. Pluim B. M. The athlete's heart: a meta-analysis of cardiac structure and function / B. M. Pluim, A. H. Zwinderma, A. van der Laarse, E. E. van der Wall // Circulation. 2000. - Vol. 101. - P. 336-344.

22. Spirito $P$. Morphology of the «athlete's heart» assessed by echocardiography in 947 elite athletes representing 27 sports / P. Spirito, A. Pelliccia, M. A. Proschan [et al.] // Amer. J. Cardiol. - 1994. - Vol. 74. - P. 802-806.

23. Vinereanu $D$. Differentiation between pathologic and physiologic left ventricular hypertrophy by tissue Doppler assessment of long axis function in patients with hypertrophic cardiomyopathy or systemic hypertension and in athletes / D. Vinereanu, N. Florescu, N. Sculthorpe [et al.] // Amer. J. Cardiol. - 2001. - Vol. 88. - P. 53-58.

24. Whelton S. P. Effect of aerobic exercise on blood pressure: a meta-analysis of randomized, controlled trials / S. P. Whelton, A. Chin, X. Xin [et al.] // Ann. Intern. Med. 2002. - Vol. 136 - P. 493-503.
11. Izzo J. Hypertension in athletes /J. Izzo // J. Clin. Hypertens. - 2009. - Vol. 11. - P. 226-233.

12. Kervancioglu P. Echocardiographic evaluation of left ventricular morphology and function in young male football players and runners /. P. Kervancioglu, E. S. Hatipoglu // Cardiol. J. - 2007. - Vol. 14. - P. 37-43.

13. Lauschke J. Athlete's heart or hypertrophic cardiomyopathy? / J. Lauschke, B. Maisch / / Clin. Res. Cardiol. 2009. - Vol. 98. - P. 80-88.

14. Lehmann M. Incidence of hypertension in 810 male sportsmen. / M. Lehmann, J. Keul // Z. Kardiol. - 1984. Vol. 73. - P. 137-141.

15. Longás Tejero M. A. Prevalence of hypertensive response to exercise in a group of healthy young male athletes. Relationship with left ventricular mass and prospective clinical implications // M. A. Longás Tejero, J. A. Casanovas Lenguas // Rev. Esp. Cardiol. - 1996. - Vol. 49(2). - P. 104-10.

16. Maron B. J. The heart of trained athletes: cardiac remodeling and the risks of sports, including sudden death / B. J. Maron, A. Pelliccia / / Circulation. - 2006. - Vol. 114. P. $1633-1644$.

17. Maron B. J. Sudden death in young athletes / B. J. Maron // N. Engl. J. Med. - 2003. - Vol. 349. P. 1064-1075.

18. Mitchell J. H. Task Force 8: classification of sports / J. H. Mitchell, W. Haskell, P. Snell, S. P. Van Camp // J. Amer. Coll. Cardiol. - 2005. - Vol. 45(8). - P. 13641367.

19. Niedfeldt M. W. Managing hypertension in athletes and physically active patients / M. W. Niedfeldt // Amer. Fam. Physician. - 2002. - Vol. 66. - P. 445-452.

20. Pelliccia $A$. The upper limit of physiologic cardiac hypertrophy in highly trained elite athletes / A. Pelliccia, B. J. Maron, A. Spataro [et al.] / / N. Engl. J. Med. - 1991. Vol. 324. - P. 295-301.

21. Pluim B. M. The athlete's heart: a meta-analysis of cardiac structure and function / B. M. Pluim, A. H. Zwinderma, A. van der Laarse, E. E. van der Wall // Circulation. 2000. - Vol. 101. - P. 336-344.

22. Spirito $P$. Morphology of the "athlete's heart» assessed by echocardiography in 947 elite athletes representing 27 sports / P. Spirito, A. Pelliccia, M. A. Proschan [et al.] // Amer. J. Cardiol. - 1994. - Vol. 74. - P. 802-806.

23. Vinereanu $D$. Differentiation between pathologic and physiologic left ventricular hypertrophy by tissue Doppler assessment of long axis function in patients with hypertrophic cardiomyopathy or systemic hypertension and in athletes / D. Vinereanu, N. Florescu, N. Sculthorpe [et al.] // Amer. J. Cardiol. - 2001. - Vol. 88. - P. 53-58.

24. Whelton S. P. Effect of aerobic exercise on blood pressure: a meta-analysis of randomized, controlled trials / S. P. Whelton, A. Chin, X. Xin [et al.] // Ann. Intern. Med. 2002. - Vol. 136 - P. 493-503. 